\title{
O PAPEL DOS GOVERNOS E DOS MECANISMOS LEGAIS NOS PROCESSOS INCLUSIVOS ESCOLARES
}

\author{
THE ROLE OF GOVERNMENTS AND OF THE LEGAL \\ MECHANISMS IN THE SCHOOL INCLUSIVE PROCESSES
}

\section{EL PAPEL DE LOS GOBIERNOS Y LOS MECANISMOS LEGALES EN LOS PROCEDIMIENTOS INCLUSIVOS ESCOLARES}

\author{
Reginaldo Celio Sobrinho \\ Edson Pantaleão ${ }^{\mathrm{I}}$ \\ Elaine de CARVALhO ${ }^{\mathrm{I}}$
}

\begin{abstract}
Resumo Este trabalho analisa a trajetória das políticas de inclusão escolar implementadas em dois municípios brasileiros, focalizando o papel dos governos locais e dos mecanismos legais nesse processo. Os dados decorrem dos grupos focais realizados durante a segunda etapa da pesquisa intitulada "Políticas de acesso e permanência de pessoas com deficiência no ensino comum: um estudo comparado de sistemas educativos brasileiros e mexicanos", concluída em 2016. As reflexões estão apoiadas nos pressupostos da Sociologia figuracional, elaborada por Norbert Elias. Os resultados nos permitem observar que as equipes de governo, por meio dos mecanismos legais, vêm atuando como importante instância de coordenação das práticas e das mudanças nas sociedades ocidentais, delineando os modos de incluir na escola. Sem perder de vista a complexidade que narra os processos inclusivos escolares em países periféricos ao capitalismo mundial, os participantes dos grupos focais sinalizaram indícios favoráveis à democratização do acesso e da permanência de alunos em situação de deficiência no contexto escolar.

Palavras-chave: Norbert Elias; Políticas de educação especial; Inclusão escolar; GoVerno; Mecanismos Legais.
\end{abstract}

${ }^{\mathrm{I}}$ Universidade Federal do Espírito Santo (UFES), Vitória/ES - Brasil. 
Abstract This study analyses the school policies' trajectory implemented in two Brazilian cities, focusing the role of the local governments and of the legal mechanisms in this process. The data were obtained from the focal groups. The process of data collecting was performed during the second stage of the research entitled "Policies of access and permanence of handicapped people in standard teaching: a compared study of Brazilian and Mexican educational systems", which was concluded in 2016. The reflections are supported by the conjectures of figurational Sociology elaborated by Norbert Elias. The results allow us to observe that government teams, through legal mechanisms, have been acting as an important instance of coordination of practices and changes in Western societies, building differents ways to include them in school. Without losing sight of the complexity of inclusive school processes in countries peripheral in relation to world capitalism, participants in the focus groups signaled a favorable elements for the democratization of access and permanence of students with disabilities in the school context.

Key-words: Norbert Elias; Special education policies; School inclusion; Government; LEGAL MECHANISMS.

Resumen El trabajo analiza la trayectoria de las políticas de inclusión escolar implementadas en dos municipios brasileños, enfocando el papel de los gobiernos locales y de los mecanismos legales en ese proceso. Los datos se derivan de los grupos focales realizados durante la segunda etapa de la investigación titulada "Políticas de acceso y permanencia de personas con discapacidad en la enseñanza común: un estudio comparado de sistemas educativos brasileños y mexicanos", concluida en 2016. Las reflexiones están apoyadas en los presupuestos de la Sociología figuracional, elaborada por Norbert Elias. Los resultados nos permiten observar que los equipos de gobierno, por medio de los mecanismos legales, vienen actuando como importante instancia de coordinación de las prácticas y de los cambios en las sociedades occidentales, delineando los modos de incluir en la escuela. Sin perder de vista la complejidad que narra los procesos inclusivos escolares en países periféricos al capitalismo mundial, los participantes de los grupos focales señalaron indicios favorables a la democratización del acceso y de la permanencia de alumnos en situación de discapacidad en el contexto escolar. Palabras clave: Norbert Elias; Políticas de educación especial; Inclusión escolar; Gobierno; Mecanismos legales.

\section{INTRODUÇÃo}

As reflexões sistematizadas neste texto constituem parte importante de um estudo comparado internacional que realizamos, entre 2014 e 2016, e que tomou como objeto de análise as políticas de acesso e de permanência de estudantes com deficiência em escolas de ensino comum localizadas nos municípios de Vitória/ES-BRA; São Mateus/ES-BRA e Xalapa/VE-MEX. Mais especificamente, neste texto temos como objetivo analisar a trajetória das políticas de inclusão escolar implementadas nos dois municípios brasileiros, focalizando o papel dos governos locais e dos mecanismos legais nesse processo. 
O debate acerca dessa questão revelou-se particularmente relevante, sobretudo quando estudando o percurso histórico de implementação das políticas educacionais, observamos que no Brasil, assim como nos demais países da América Latina, os processos relativos à expansão e à obrigatoriedade do ensino assemelham-se em muitos aspectos, destacando-se as influências e as intervenções das agências internacionais como o Banco Mundial e o Banco Interamericano de Desenvolvimento.

Elias (1993) nos ajuda a compreender a crescente e indispensável centralidade assumida por essas agências internacionais, mostrando-nos que, em diferentes momentos da história, as distintas sociedades organizaram-se em torno de órgãos centrais com capacidade de regular as cadeias de ações de indivíduos e grupos. O autor nos informa que o que denominamos "feudalismo", por exemplo, manifestava uma estrutura organizacional reguladora baseada em significativos graus de dependência funcional entre os indivíduos naquela sociedade específica. O processo social que mais tarde impulsionou a consolidação do Estado moderno como nova forma de governo teve estreita vinculação com o fato de que, paulatinamente "[...] a moeda, e não mais a terra, tornou-se a forma dominante de propriedade" (ELIAS, 1993, p. 142). Ademais, no bojo desse processo de mudança social, encontravam-se as forças econômicas e sociais burguesas que, apoiadas em dispositivos políticos e legais, colaboraram na consolidação de um modelo de sociedade, organizado em torno da apropriação máxima de lucros privados (HOBSBAWM, 2015).

Nessa dinâmica social, o poder do governante monopolista, doravante centralizado na "posse privada" de um único soberano (ou de um pequeno círculo de pessoas), passava gradativamente a ser coordenado por um círculo maior de indivíduos (ELIAS, 1993), delineando o que Hobsbawm (2015) definiu como a vitória da dupla Revolução - a Francesa e a Industrial capitalista. Assim é que, crescentemente, as tensões vividas faziam emergir a necessidade da constituição de órgãos centrais dotados de forte estabilidade e com evidentes implicações na condução geral dos processos sociais vividos em regiões cada vez mais vastas.

Portanto, diferentemente de outras sociedades, na história ocidental notamos que a constituição dos órgãos centrais reguladores decorreu de um processo lento e constante que intensificou a diferenciação e a especialização do conhecimento e do trabalho, de maneira que chegamos a uma situação social em que as atividades humanas inter-relacionadas " [...] simplesmente não podiam continuar a crescer, ou sequer funcionar, sem órgãos de coordenação em um nível correspondentemente alto de organização" (ELIAS, 1993, p. 142). Vale considerar que, segundo Elias (1993), esses órgãos centrais (e o grupo social que estes representam) somente se estabeleceram na forma de governo, coordenando um vasto território e um diversificado contingente populacional, porque sua existência esteve pautada em duas características complementares: a primeira se refere à importância que esses órgãos centrais têm para o "funcionamento" da rede humana no contexto das complexas redes da modernidade; a segunda diz respeito ao poder social desses órgãos, ou seja, à capacidade que eles têm de preservar continuamente os outros grupos, na condição de dependentes de sua coordenação. 
Outro importante aspecto a considerar no processo de consolidação do Estado moderno é a construção de conceitos como nação, nacionalidade, direito e cidadania. Nesse viés, surge a compreensão de que, somente por meio de um conjunto de leis estruturadas (de determinada nação) e por intermédio da criação e preservação dos direitos sociais, é que definitivamente o conceito de cidadania pode ser desenvolvido, estando todos os cidadãos, sem exceção, submetidos a uma legislação nacional. Essa concepção chamada de Estado de direito contrapunha-se ao autoritarismo exposto ao longo do Antigo Regime, que foi expresso, por exemplo, na famosa frase de Luís XIV: “O Estado sou Eu”.

Ao longo dos séculos XVII ao XX, foi possível acompanhar o lento processo de consolidação dos Estados modernos e sua intrínseca relação com o conceito de nacionalismo. É importante considerar que tal conceito não se reduz ao delineamento das fronteiras geográficas, tampouco aos aspectos biológicos de cada povo, nem linguísticos, nem mesmo econômicos, mas deve ser interpretado sob os ares sociopsicológicos (RENAN, 2000). Dessa forma, configuravam-se no habitus das sociedades certos sentimentos que, aos poucos, definiam o "eu" dos "outros", instigando emoções que deliberavam a nacionalidade de cada um.

Nesse mesmo período (de consolidação dos Estados-Nação), o monopólio da tributação e da força militar, articulado à constituição de aparelhos especializados para a sua administração, possibilitou a instauração de governos locais estáveis (ELIAS, 1993). Contudo, mais precisamente desde meados do século XIX e ao longo do "breve"1 século XX, conforme bem definiu Hobsbawm (1995), vimos ocorrer os crescentes conflitos internacionais, associados ao processo imperialista de disputa pela hegemonia econômica realizada pelas principais nações capitalistas europeias, asiáticas e pela crescente ascensão estadunidense no cenário econômico e militar. Ao final da Segunda Guerra Mundial, esse país, em especial, posicionou-se em local de destaque entre as principais nações capitalistas, com evidente capacidade de influenciar e de intervir nas decisões internacionais. Esse poderio estadunidense gerou condições para a organização de agências bilaterais e multilaterais que, mais tarde, puderam encarregar-se de assegurar a estabilidade política e a preservação da ordem geopolítica internacional (MOTA JUNIOR, MAUÉS, 2014).

Assim, no curso do século XX e particularmente desde a década de 1980, o Banco Mundial foi redimensionando suas funções, atuando como coordenador do processo global de desenvolvimento e fomentando programas de assistência técnica e financeiras aos países subdesenvolvidos (FONSECA, 1998). Essa dinâmica tem possibilitado que, não sem tensões e resistências, ao longo das duas últimas décadas, os organismos internacionais atuem como uma forma muito peculiar de governo por meio de acordos e tratados internacionais e coordenem a implementação das políticas sociais em diferentes países, sobretudo naqueles periféricos ao capitalismo mundial.

Assentados na compreensão de que as injustiças sociais decorrem fundamentalmente das disparidades educacionais, esses organismos trabalham sob a expectativa de que a eco-

No livro "A Era dos Extremos: o breve século XX", o historiador Eric J. Hobsbawm faz um ensaio sobre os acontecimentos marcantes do século XX, iniciando sua marcação histórica, em 1914, com a Primeira Guerra Mundial e encerrando a sua análise com a queda do muro de Berlim, em 1989. 
nomia globalizada, ancorada no conhecimento, precisa ter a educação como tema central, para assegurar um futuro com menos desigualdade social na América Latina (SANDER, 2005; TELLO, MAINARDES, 2014). No entanto, defendem que, em virtude de uma modernização exigida pelo mercado competitivo, no decorrer natural da liberalização econômica, cada indivíduo teria a possibilidade de garantir por si mesmo essas necessidades, o que promoveria um generalizado melhoramento da questão social (VALADÃO, 1997). Assim, em uma aparente contradição do discurso, esses organismos gerenciadores promoveram a ampliação dos direitos sociais quanto ao acesso educacional por meio de incentivo à criação de leis que estabelecem, por exemplo, a obrigatoriedade do ensino por toda a América Latina, sem, contudo, privilegiar a qualidade social da educação e sem deixar de favorecer os setores privados no campo do mercado da educação.

No fluxo desse processo, portanto, sem escapar às orientações dessas instituições, o Brasil figura entre os signatários dos acordos internacionais assinados no curso das últimas décadas. E, nesse sentido, vem assumindo, por meio de suas diretrizes legais, o compromisso de garantir o direito à educação escolar também às pessoas com deficiência, respondendo aos preceitos e indicações das agências multilaterais.

Impulsionados por essas questões e envolvidos diretamente no campo de estudos da educação especial, vimos estudando, no curso dos últimos anos, aspectos mais gerais sobre as desigualdades sociais e educativas vividas em realidades latino-americanas, tomando como ponto de partida a dinâmica educativa desenvolvida em escolas de ensino comum que contam com a matrícula de pessoas com deficiência.

Conforme destacamos, em 2016 concluímos a pesquisa intitulada "Políticas de acesso e permanência de pessoas com deficiência no ensino comum: um estudo comparado de sistemas educativos brasileiros e mexicanos". ${ }^{2}$ Esse trabalho investigativo esteve orientado teoricamente pelos pressupostos da Sociologia figuracional, elaborada por Norbert Elias, em diálogo com a literatura que versa sobre as políticas educacionais e a respeito da pertinência dos Estudos Comparados Internacionais em Educação (FERREIRA, 2008; CARVALHO, 2014).

Vinculado a essa investigação, o estudo sistemático das obras de Norbert Elias tem nos ajudado a superar o sentido técnico e estático que recorrentemente vem sendo atribuído à noção de política. De fato, interessado no estudo das transformações sócio-históricas, Elias (1993, p. 37) destaca que, "[...] na história, nenhum fato isolado produz por si mesmo qualquer transformação, mas apenas em combinação com outros". Complementarmente, alerta-nos que, "[...] quando pesquisamos processos sociais, temos que examinar a rede de relacionamentos humanos, a própria sociedade, a fim de identificar as compulsões que as conservam em movimento e lhes conferem forma e direção particulares [...]" (ELIAS, 1993, p. 38). Assim é que, em Elias (1993), termos como "absolutismo", "capitalismo", "economia de trocas", "economia monetária" trazem sentidos históricos e sociais que dizem respeito às mudanças nos relacionamentos humanos e na constituição das próprias pessoas.

\footnotetext{
Pesquisa financiada pelo CNPq.
} 
Ao assumirmos essa perspectiva histórico-sociológica, compreendemos a política como um espaço-tempo, cuja dinâmica comporta a coexistência velada e/ou explícita de interesses congruentes, ambíguos e contraditórios que orientam os modos de organizar a vida em sociedade. Constituindo-se, no mais das vezes, como um importante dispositivo na manutenção e/ou na transformação de uma situação social vivida. Decorre daí a nossa compreensão de que, embora constituam importantes aspectos da política, o trabalho das equipes de governo e os mecanismos legais não são, por si só, a política.

Levar a efeito essa perspectiva implica não perder de vista que não existe uma política "lá fora" exercida e coordenada "pelos outros". Em diferentes contextos e realidades, a política assume dimensões mais simples e diretas, ou mais abrangentes e complexas, num jogo social marcado por avanços, recuos, rupturas, continuidades e/ou descontinuidades, do qual todos nós participamos direta ou indiretamente. Orientados por essa compreensão é que consideramos importante investigar as políticas educacionais articuladas às trajetórias dos sujeitos e dos grupos envolvidos em sua implementação.

Para o cumprimento do proposito deste texto, na sequência apresentamos os delineamentos metodológicos da pesquisa desenvolvida nos municípios, destacando as características do estudo e das duas realidades que compõem o foco de análise neste texto. Em seguida, passam a ser foco das nossas análises os discursos e as percepções dos sujeitos sobre a inclusão escolar que se vem realizando mediante as políticas educacionais locais. Por fim, apontamos considerações que o estudo nos proporcionou.

\section{Delineamento Metodológico do estudo}

Como resultado do projeto de pesquisa intitulado "Políticas de acesso e permanência de pessoas com deficiência no ensino comum: um estudo comparado de sistemas educativos brasileiros e mexicanos", neste texto priorizamos sistematizar dados produzidos com base na realização dos grupos focais em dois municípios brasileiros ${ }^{3}$ - Vitória e São Mateus.

A pesquisa desenvolveu-se mediante a articulação interinstitucional que estabelecemos com um grupo de investigadores da Universidade Veracruzana (MEX), com profissionais da educação da Diretoria de Educação Especial do Estado de Veracruz (MEX) e com profissionais dos setores de educação especial dos municípios de Vitória e São Mateus. Assim, procurou-se analisar os processos inclusivos escolares vividos nas três realidades municipais envolvidas na pesquisa.

Ademais, é importante destacar o processo de universalização da educação escolar que tem sido intensificado no Brasil e no México, desde as últimas décadas do século XX. Esse movimento tem provocado um processo de redefinição do papel do Estado no âmbito da execução das políticas sociais. Associados a esse aspecto, nos dois países, em virtude da perspectiva da inclusão social e escolar, os papéis e as funções da escola comum assumiram diferentes contornos, o que tem provocado mudanças na organização e na estrutura das

3 No total, a pesquisa envolveu três municípios. No Brasil, os municípios de Vitória e São Mateus, no Estado do Espírito Santo; e, no México, investigamos o município de Xalapa, Estado de Veracruz. 
ofertas dos diferentes níveis, etapas e modalidades de educação, influenciando a trajetória escolar dos estudantes público-alvo da educação especial.

É importante considerar, ainda, que é restrito o número de pesquisas que problematizam o papel do poder público municipal no direcionamento de políticas que buscam a garantia de oferta de recursos e de serviços à população com deficiência (SOTO et al., 2012). Isso nos indica a pertinência de estudar diferentes realidades municipais, pois proporciona a possibilidade da produção de conhecimento que contribua para a melhor compreensão sobre as políticas públicas municipais no atendimento ao direito à educação de todos. Assim é que, no escopo do estudo realizado, vale contextualizar, ainda que brevemente, a realidade educacional dos dois municípios que focalizamos neste texto.

O município de Vitória, capital do Estado do Espírito Santo, tem uma área territorial de $96,536 \mathrm{~km}^{2}$, contando com uma estimativa populacional para 2016 de 359.555 habitantes. ${ }^{4}$ Em 2016, o poder público do município mantém 49 centros municipais de educação infantil e 54 escolas municipais de ensino fundamental. Nessas escolas, registra-se a matrícula de 1.110 estudantes público-alvo da educação especial, sendo 190 matriculados na educação infantil e 920 no ensino fundamental (MILANEZI, 2016).

São Mateus tem uma área territorial de $2.338,733 \mathrm{~km}^{2}$ e contava, segundo estimativa de 2016, com uma população de 126.437 habitantes. ${ }^{5}$ Considerado como o oitavo município mais populoso do Estado do Espírito Santo, a administração municipal organiza as atividades de ensino em 37 centros de educação infantil e 32 escolas de ensino fundamental. Nessas escolas, observa-se um total de 213 matrículas de estudantes público-alvo da educação especial, sendo 25 na educação infantil e 188 no ensino fundamental (ZIVIANI, 2016).

Nesses dois municípios, os serviços especializados de educação especial são ofertados nas salas de recursos multifuncionais. Nesses espaços, os professores especializados em educação especial desenvolvem atividades complementares e/ou suplementares com estudantes que têm diagnósticos ${ }^{6}$ de deficiência, de transtornos globais de desenvolvimento e/ou altas habilidades/superdotação. Em conformidade com a política nacional de educação especial na perspectiva inclusiva (BRASIL, 2008), as salas de recursos multifuncionais contam com equipamentos, mobiliários, material pedagógico e de acessibilidade destinados a atender às especificidades educacionais desse grupo específico de estudantes.

No percurso da investigação nos municípios, atribuímos pertinência ao uso de diferentes instrumentos e procedimentos de coleta de dados - grupos focais, visitas aos espaços específicos onde o fazer administrativo e pedagógico se encontra em ação, entrevistas, estudo de documentos e da bibliografia da área da educação especial. Assim, a pesquisa foi desenvolvida em duas etapas. Na primeira, realizamos visitas técnicas aos diferentes ór-

$4 \quad$ Disponível em: $<$ http://www.cidades.ibge.gov.br/xtras/perfil.php?lang=\&codmun=320530\&search=espiri to-santo|vitoria>. Acesso em: 25 jul. 2017.

5 Disponível em: $<$ http://www.cidades.ibge.gov.br/xtras/perfil.php?lang=\&codmun=320490\&search=espiri to-santo|sao-mateus $>$. Acesso em: 25 jul. 2017.

6 Nos dois municípios investigados, os estudantes são atendidos nas salas de recursos multifuncionais tanto a partir de diagnóstico clínico realizado por profissionais da área de saúde (médicos e psicólogos), quanto a partir de avaliação pedagógica feita pelos profissionais especialistas do Atendimento Educacional Especializado. 
gãos, setores e instituições públicas dos municípios foco do estudo, acessamos documentos oficiais que esclareciam a política educacional implementada e entrevistamos profissionais que atuam nos setores de educação especial e em escolas de ensino comum dos municípios foco do estudo.

$\mathrm{Na}$ segunda etapa de investigação, constituímos grupos focais em cada um dos municípios, buscando um contato direto com os sujeitos que praticam e vivenciam os processos inclusivos escolares nas localidades investigadas. Conforme destacamos, os dados contidos neste texto são originários desse segundo momento investigativo, realizado nos municípios de Vitória e São Mateus.

Diferentes autores (GONDIM, 2003; GATTI, 2005; COSTA, 2012; HAMUI-SUTTON; VARELA-RUIZ, 2013) argumentam que os grupos focais possibilitam o estudo das atitudes, ideias, crenças, valores que orientam as experiências sociais dos sujeitos investigados. Hamui-Sutton e Varela-Ruiz (2013, p. 56), especialmente, esclarecem que os grupos focais possibilitam diferentes formas de exploração dos conteúdos e dos temas que orientam as investigações. Esses autores alegam que o grupo focal "[...] facilita la discusión y activa a los participantes a comentar y opinar aún en aquellos temas que se consideran como tabú, lo que permite generar una gran riqueza de testimonies".

Para Gondim (2003), a dinâmica dos grupos focais ajuda tanto na elaboração de hipóteses quanto na elaboração e/ou no melhoramento de outros instrumentos que, associados a essa dinâmica coletiva de coleta de dados, auxiliam maior aprofundamento das questões abordadas no curso de uma investigação específica. Além disso, o grupo focal tem a potencialidade de gerar um espaço de interação pautado na espontaneidade, na empatia e na colaboração entre os participantes, que não precisam responder a cada uma das questões apresentadas (HAMUI-SUTTON; VARELA-RUIZ, 2013).

O grupo focal, para Gatti $(2005$, p. 9), "[...] permite fazer emergir uma multiplicidade de pontos de vista e processos emocionais, pelo próprio contexto de interação criado, permitindo a captação de significados que, com outros meios, poderiam ser difíceis de manifestar".

Embora esse espaço grupal possa trazer elementos que auxiliem a ressignificação das crenças e das perspectivas dos participantes, em geral, suas posições expressam as concepções de homem, de mundo e de sociedade que fundamentam as experiências sociais e culturais que orientam as inter-relações que eles experimentam cotidianamente (SANTOS; PORRO, 2008). Esse aspecto impõe a necessidade de os dados coletados, por meio dos grupos focais, serem submetidos a uma análise de maneira contextualizada, e nunca deslocados dos processos sociais vividos.

Nos grupos focais que realizamos, contamos com a participação de pais/familiares de estudantes com deficiência matriculados no ensino comum, de profissionais que atuam no Atendimento Educacional Especializado em educação especial, de professores do ensino comum, da equipe de gestão escolar e gestores dos setores de educação especial. Considerando a nossa intencionalidade investigativa, organizamos os grupos focais em seis eixos de discussão, a saber: 
a) a escola como espaço de aprendizagem;

b) as oportunidades de aprendizagem vividas pelos estudantes com deficiência no ensino comum;

c) a participação conjunta de pais e profissionais do ensino na escolarização de estudantes com deficiência;

d) a trajetória das políticas de inclusão escolar;

e) preocupações dos profissionais que atuam na administração pública sobre o processo de concretização de uma escola para todos;

f) a dinâmica de intersetorialidade nos processos educativos de estudantes com deficiência.

Com o propósito de sistematizar reflexões sobre essas questões, neste texto reunimos registros dos momentos dos grupos focais, atentando para as declarações dos participantes quando evidenciavam questões relativas à trajetória das políticas de inclusão escolar e focalizando o papel dos governos locais e dos mecanismos legais nesse processo.

\section{OS DISCURSOS E AS PERCEPÇões dOS SUJEITOS SOBRE A POLÍTICA DE INCLUSÃO}

Respondendo e debatendo sobre as diferentes questões que apresentávamos, em diferentes momentos os participantes dos grupos focais avaliavam a trajetória das políticas de inclusão escolar que vem se implementando em Vitória/ES e em São Mateus. Manifestavam uma compreensão de que "há um processo em curso" com possibilidades de trazer melhorias para a educação escolar dos estudantes com deficiência. Assim, de certa maneira, avaliaram positivamente a dinâmica de inclusão escolar vivida. Em seus relatos, alguns participantes disseram:

[...] a gente pode ver que, nas últimas décadas, houve um grande avanço. Houve um avanço, porque, quando a gente fala de história, de avanços históricos, que permeiam toda uma política, o tempo é um tempo diferente da nossa vida, né? Então, eu me lembro de que, enquanto criança, o contexto e a quantidade de pessoas com deficiência no ambiente educacional era muito menor, hoje a gente já vê uma inclusão, uma abertura maior [...] (PROFESSORA 1 DO ENSINO COMUM DO MUNICÍPIO DE VITÓRIA).

[...] Aqui na rede municipal, é lógico que a gente tem muito ainda a conquistar, mas vem tendo sim um suporte, até mesmo para os profissionais da área [...]. Eles têm redução de carga horária para poder dar um apoio maior para essas crianças. Então eu vejo assim, tem muito a se construir? Tem, mas já existe um diálogo que eu penso que em décadas passadas não existia (PROFESSORA 3 DO ENSINO COMUM DO MUNICÍPIO DE VITÓRIA).

Compartilhando a visão otimista sobre esse processo, duas representantes do setor de Educação Especial da Secretaria do município de Vitória expressaram-se nos seguintes termos:

[...] a escola por muitos anos foi seletiva, então agora a gente vem num

Comunicações | Piracicaba | v. $25 \mid$ n. $1 \mid$ p. 195-216| janeiro-abril 2018203 
movimento inverso trazendo todas as crianças, todas as pessoas para a escola. Garantindo o direito à educação, inclusive às pessoas com deficiência. E nesse processo há necessidade de uma modificação dessa escola, que a gente vem num processo de mudança gradativa e muitas vezes lenta [...] (TÉCNICA 2 DO SETOR DE EDUCAÇÃO ESPECIAL DO MUNICÍPIO DE VITÓRIA).

[...] ainda falta muito para avançar. Realmente falta, mas quando a gente faz uma análise histórica da educação de um modo geral no Brasil, onde mais avançou foi na Educação Especial [...] (TÉCNICA 1 DO SETOR DE EDUCAÇÃO ESPECIAL DO MUNICÍPIO DE VITÓRIA).

Corroborando a compreensão de que "há um processo em curso", no grupo focal realizado no município de São Mateus, dois participantes posicionaram-se da seguinte forma:

[...] eu estou aqui na Educação Especial desde o primeiro semestre de 2013, e hoje eu vejo com muita satisfação o avanço que a gente já conseguiu (TÉCNICA 1 DO SETOR DE EDUCAÇÃO ESPECIAL DO MUNICÍPIO DE SÃO MATEUS).

[...] Eu fico feliz porque é o primeiro ano que a minha filha 'tá sendo incluída na escola. E a gente está tendo assim, um avanço grande, estou gostando, né. A cuidadora, a professora, a professora Isabel, que é da sala de recursos, estão muito envolvidas. Então a gente encontrou uma coisa que a gente não esperava encontrar na escola [...] (FAMILIAR 4 DO MUNICÍPIO DE SÃO MATEUS).

O debate que nos propusemos realizar neste texto implica considerar que a inclusão social e a inclusão escolar são uma construção do Estado moderno, recorrentemente, conforme vimos, também denominado como Estado de direito. Para nós, o longo percurso histórico de consolidação e de legitimação dessa perspectiva de Estado, delineado por tensões e resistências, sustenta e direciona as mudanças sociais ocorridas no curso dos últimos séculos em nossas sociedades ocidentais, destacando-se nesse processo o reconhecimento das pessoas com deficiência como sujeitos de direitos.

Nessa dinâmica, no Brasil, ainda fortemente apoiada em flagrantes disparidades e desigualdades sociais e econômicas, a educação escolar vem gradativamente constituindo-se como um importante direito social que deve ser assegurado a todas as pessoas, independentemente de sua condição social, econômica, étnica, religiosa e/ou de essas pessoas viverem em situação de deficiência. Nesse sentido, é interessante notar que a atuação dos governos locais na trajetória de implementação das políticas de inclusão escolar, embora controversa, não deixa de ser percebida positivamente por muitas pessoas, grupos e instituições.

Assim é que, ao avaliarem o processo de inclusão escolar de pessoas com deficiência, os participantes dos grupos focais explicitaram a importância da ação estatal, apontando que têm observado existir, por parte dos governos, certo reconhecimento dos direitos dessas pessoas. Isso pode ser expresso no "[...] aumento da quantidade de pessoas com deficiência no ambiente educacional $[\ldots]$ ”, na oferta de "[...] um suporte, até mesmo para 
os profissionais da área [...]", na abertura para o diálogo sobre as necessidades e demandas educativas das pessoas com deficiência e na medida em que os pais encontram "[...] o que não esperavam encontrar na escola [...]".

No cumprimento dos propósitos deste texto, vale destacar a nossa percepção de que a administração pública, erigida como uma forma específica de governo vem atuando como um importante dispositivo de coordenação das práticas e das mudanças sociais nas sociedades ocidentais. Conforme destacamos inicialmente, encontramos em Elias (1993) indicações que nos ajudam a compreender que a centralidade assumida pelos governos locais em nossas sociedades recentes diz respeito à combinação de eventos sociais que, em longa duração histórica, possibilitaram a organização de um aparelho administrativo cada vez mais especializado, com potencial para coordenar o monopólio da tributação e da força militar exercido pelo Estado.

Mais exatamente, Elias (1993) salienta que a ampliação do poder social dos governos, como órgãos centrais, no escopo do Estado moderno, se deve ao entrelaçamento de diferentes eventos sociais, como a intensificação do uso da moeda, a diferenciação e a especialização do trabalho, a formação e a ampliação de mercados, a monopolização estatal dos impostos e da força física, o excesso demográfico, a legitimação das competições não livres, a instauração do regime democrático, o crescimento das cidades e o orçamento público como dispositivo governamental. Sem perder de vista o exame dos sentimentos dos indivíduos, o autor observa que esses eventos sociais estiveram marcados pela emersão de uma ambivalência declarada ou latente nos relacionamentos humanos, com evidentes consequências na vida política e na constituição psicológica dos indivíduos. Assim, de modo muito específico, no fluxo das tensões vividas nas inter-relações sociais, uma multiplicidade de interesses cada vez mais complexos e contraditórios, balizados por uma leve e/ou explícita combinação de dedicação, afeição, animosidade e rancor em dimensões mutáveis e incertas, ampliava e aprofundava a interdependência social. O autor esclarece-nos que, diferentemente do que ocorria em momentos anteriores, nessa fase de gradativa consolidação dos Estados-Nação,

\footnotetext{
[...] as possibilidades de inimizade pura, inequívoca, diminuem e se evidencia mais e mais o quanto os atos cometidos contra um adversário ameaçam também a existência social de quem os perpetra, perturbando assim o mecanismo inteiro das cadeias de atos, das quais todos são partes [...] (ELIAS, 1993, p. 145).
}

Elias (1993) destaca que essa ambivalência estrutural nas inter-relações sociais representou um importante referente para a modelação das condutas humanas e para o estabelecimento de uma autoridade central ancorada na forma de governo que se desenvolveu nas sociedades modernas. $\mathrm{O}$ autor evidencia, assim, um princípio geral que conforma centralização e ambivalência de interesses em um mesmo processo que deu os contornos do Estado moderno, como o conhecemos atualmente: 
torna tão grande e o poder é tão uniformemente distribuído entre eles, que não pode haver nem uma solução conciliatória decisiva nem um conflito decisivo entre eles (ELIAS, 1993, p. 148).

Desse modo, curiosamente, com o estabelecimento do Estado moderno, as questões impulsionadoras das tensões sociais não se referem à eliminação da forma de governo implementada, mas dizem respeito, muito mais, a quem deve controlar o Estado, bem como, a instrumentos que podem ser utilizados para a constituição das equipes governamentais e para a distribuição dos benefícios decorrentes dos monopólios, agora firmemente estabelecidos (ELIAS, 1993). Nesse aspecto, é fundamental não perder de vista que, desde o fim do século XIX, a educação escolar figura como um importante monopólio do Estado. De fato, no curso dos últimos três séculos, na medida em que passava a ser compreendida como espaço por excelência de socialização de saberes e de disseminação dos ideais de nação e de pátria, paulatinamente a universalização e a obrigatoriedade escolar foram estabelecendo-se como condição para o alcance do progresso social das nações modernas; portanto, como uma importante responsabilidade dos governos (HONORATO, 2014; VEIGA, 2014; GEBARA, 2014).

Não sem razão, associados à estrutura burocrática estatal, os mecanismos legais instituídos e seus modos de implementação pelas equipes de governo, via de regra, constituem-se como importantes referentes em nosso modo de avaliar a inclusão escolar em nossas sociedades recentes. Assim, observamos que, durante os debates que desenvolvemos sobre as preocupações dos profissionais que atuam na administração pública a respeito do processo de concretização de uma escola para todos, os participantes dos grupos focais atribuíram importância aos mecanismos legais estabelecidos pelos governos, colocando em evidência a função legislativa estatal. Nessa direção, argumentaram:

[...]. Houve avanço nas questões sociais, houve avanço na legislação também, e já se podem perceber algumas conquistas. E, mesmo que haja demora, eu sou ouvida e levada em consideração [...] (FAMILIAR 1 DO MUNICÍPIO DE VITÓRIA).

[...] Seu filho é obrigado a estar matriculado, digamos assim, de acordo com as diretrizes do Estado. E você tem de estar aqui, se você não estiver aqui, vamos chamar o Conselho Tutelar, alguma coisa tem que ser feita nesse sentido. Não pode deixar seu filho fora da escola. A escola não pode se acomodar com um pai omisso. Tem esse lance, tem essa questão também. Eu acho importante isso (FAMILIAR 2 DO MUNICÍPIO DE VITÓRIA).

[...] nós temos conhecimento que o Estado, o Poder Público, tem condições de fazer muito. Fazer muito pelas nossas crianças, pelas nossas famílias. Então cabe a gente conhecer um pouco a lei e buscar isso. Temos que cobrar [...]. $\mathrm{Eu}$, enquanto professora, tenho que cobrar. E conhecer as leis, né, também, porque, se a gente não conhecer as leis, a gente se torna leigo nesse tipo de situação [...] (PROFESSORA 3 DO ENSINO COMUM DO MUNICÍPIO DE SÃO MATEUS). 
[...] E o interessante que eu vejo é que alguns pais que têm crianças com necessidades especiais, eles conhecem muito a lei. É muito legal isso aí. A maioria deles sabe dos seus direitos e corre atrás (TÉCNICA 2 DO SETOR DE EDUCAÇÃO ESPECIAL DO MUNICÍPIO DE SÃO MATEUS).

Essas declarações direcionam as nossas reflexões para um importante dispositivo organizador da vida em nossas sociedades recentes, do qual a educação escolar não escapa. Trata-se da criação das leis. A esse respeito, Elias (1993) destaca que, somente em sociedades dotadas de um grau muito avançado de integração social, encontramos instituições centrais fortes com capacidade de elaborar e exigir o cumprimento de acordos escritos em toda a área que controlam. É interessante notar que, nessas realidades sociais, a lei se apresenta como algo absoluto que dispensa explicação e que se impõe ao cotidiano dos indivíduos, independentemente da estrutura de poder vivida sob esta ou aquela forma de governo geral (ELIAS, 1993).

Complementarmente, o autor pontua que a lei delineia e expressa a especificidade do equilíbrio de poder vivido nas diferentes figurações sociais. Em outros termos, as formas legais constituem símbolos sociais que se instituem e somente alcançam legitimidade em íntima associação e dependência da estrutura social que é compartilhada por indivíduos e grupos num espaço e em momentos específicos. Nesse sentido, compreendemos que o exercício da função legisladora do Estado, expressa nas ações das equipes de governo, vem direcionando as práticas inclusivas escolares. Essa função estatal repercute na crença compartilhada entre os participantes dos grupos focais de que os avanços na legislação, em termos de obrigatoriedade da matrícula escolar, vêm favorecendo os diálogos entre pais e profissionais do ensino, mas também impondo a necessidade de conhecer as leis e de a escola, por exemplo, não "[...] se acomodar com um pai omisso [...]".

Os mecanismos legais vão delineando a percepção social dos indivíduos. Compreendemos, assim, que a função e a pertinência social dos mecanismos legais se delinearam dentro de um largo processo que compreendia a imbricação de muitas outras mudanças sociais em curso. Abalizadas por tensões e ambiguidades, essas mudanças sociais se sustentaram nas alterações específicas ocorridas nas redes dos relacionamentos humanos, ao mesmo tempo em que orientavam a constituição pessoal dos indivíduos envolvidos nessa rede. Essa perspectiva histórico-social vem nos ajudando a compreender melhor a razão pela qual, ao tematizarem a escola como espaço de aprendizagem, os participantes dos grupos focais avaliaram a inclusão escolar, percebendo as ações das equipes de governo como importante referência.

Nesse sentido, observamos que, quando debatemos sobre a dinâmica de intersetorialidade vivida nos processos educativos de estudantes com deficiência, bem como, a respeito da trajetória das políticas de inclusão escolar, os participantes dos grupos focais não deixaram de considerar dificuldades e dilemas muito evidentes na concretização do que as legislações e diretrizes orientam. Entre outras questões, problematizaram a concretização do direito pleno de cidadania no âmbito dos direitos sociais. Em suas reflexões, sinalizaram que: 
[...] a gente reconhece que houve avanços na legislação, mas ainda não foi o suficiente para garantir, né, o atendimento de qualidade. Avançou, mas ainda precisa avançar mais. Avançou na legislação, mas a gente ainda continua vendo coisas que deveriam ser feitas e que ainda não são feitas. Tem a legislação, mas na prática ainda não existe tudo que deveria acontecer (TÉCNICA 1 DO SETOR DE EDUCAÇÃO ESPECIAL DO MUNICÍPIO DE VITÓRIA).

[...] eu penso também assim, enquanto setor de Educação Especial, que a gente ainda tem muita coisa para avançar: questões de legislação, questão de acompanhamento clínico, porque, às vezes, a gente esbarra numa situação clínica, que precisa desse acompanhamento (TÉCNICA 2 DO SETOR DE EDUCAÇÃO ESPECIAL DO MUNICÍPIO DE SÃO MATEUS).

Associados a essas indagações, os participantes questionaram a concretização das políticas públicas. Reiteradamente explicitavam que as ações governamentais, efetivamente, não seguiram o mesmo ritmo das mudanças vividas na escola, tão necessárias para garantir melhores condições de realizar a inclusão escolar. Destacaram a morosidade do poder público no atendimento às demandas da realidade escolar, dificultando a materialização e a concretização dos princípios e indicativos dos direitos sociais definidos nas legislações. Assim, argumentaram:

[...] Eu concordo com a professora aqui, quando ela colocou as questões que já vêm sendo feitas. Agora, o meu questionamento com relação ao poder público é que as coisas ainda são muito morosas. Tudo demora muito para chegar à escola. E isso precisa mudar, né? (TÉCNICA 2 DO SETOR DE EDUCAÇÃO ESPECIAL DO MUNICÍPIO DE VITÓRIA).

[...] E aí o problema, ou talvez, não seja o problema. A questão das políticas públicas, pois elas estão acontecendo há pouco tempo. As políticas públicas não têm acompanhado esse ingresso de todas as crianças nas escolas, algumas acabam ficando de fora, ou não sendo atendidas nas suas necessidades [...] (PROFESSORA 4 DO ENSINO COMUM DO MUNICÍPIO DE VITÓRIA).

Nós somos o grupo dos gestores. Nós entendemos que a política pública avançou muito, mas ainda precisamos concretizar essas ideias. Está garantida na legislação, mas ainda precisa ser concretizada na prática, precisamos avançar para que, de fato, as crianças consigam ser atendidas com qualidade nas escolas (TÉCNICA 1 DO SETOR DE EDUCAÇÃO ESPECIAL DO MUNICÍPIO DE VITÓRIA).

Durante as discussões que se desenvolveram nos grupos focais, os participantes também enfatizaram questões relativas à dificuldade vivenciada pela escola para a oferta de atividades e de espaços que possam atender às demandas das pessoas com deficiência. Em algumas situações, avaliaram a atitude dos profissionais da escola da seguinte forma: 
[...] a escola tem que saber receber essas crianças, porque, igual o que eu escutei do diretor, não pode ser. Ele não sabia o que era autismo e disse que não sabia lidar com aquilo. Gente, isso é um absurdo! Ele tem que saber [...]. Eu faço a minha parte, enquanto família. Quem tem que fazer a sua parte de escola é você, não sou eu, assim eu falei para ele (FAMILIAR 2 DO MUNICÍPIO DE VITÓRIA).

Em outros momentos, destacaram a necessidade de ampliação do quantitativo de profissionais para atuar na escola que se pretende inclusiva. Questionaram a falta de práticas pedagógicas condizentes com o processo colaborativo na sala de aula, pois, com poucos profissionais disponíveis na escola, o planejamento do professor especialista com o professor do ensino comum fica prejudicado, bem como, o acompanhamento e o trabalho pedagógico com o aluno que o professor especialista deveria fazer em sala de aula. Na avaliação de uma professora especialista do município de Vitória,

[...] a proposta que a secretaria traz acaba sendo incompatível diante da carência de pessoal. Como propor um trabalho colaborativo? Não há tempo para isso. Desenvolver um trabalho de qualidade, como a gente gostaria [...]. E ficamos refém dos estagiários porque os estagiários acabam sendo a nossa extensão para a gente saber o que está se passando dentro de sala de aula. Então eu acho que é preciso pensar nessa questão. Precisamos de um quantitativo de profissionais que seja compatível com uma proposta pedagógica inclusiva (PROFESSORA ESPECIALISTA 2 DO MUNICÍPIO DE VITÓRIA).

Problematizando mais o cotidiano escolar, alguns participantes do grupo focal observaram a precariedade das condições objetivas do trabalho da escola, tendo em vista desenvolver o processo educativo com todas as crianças. Uma mãe, munícipe de São Mateus, relata a situação da filha:

[...] A gente tem dificuldade de ficar com ela [referindo-se à filha] na cadeira na sala de recursos. Na escola, a gente vai, só que tem outra dificuldade, quando está muito quente, as crianças que se locomovem, andam. Elas não sentem o calor que ela [a filha] sente por ter que ficar em uma cadeira o tempo todo. Quatro horas numa cadeira! E tem mais, a escola é baixinha, de "eternit", entendeu? Esquenta muito! Tem os ventiladores, mas que não suportam. A gente percebe que às vezes ela fica agoniada, cansadinha, mais é de calor, entendeu? Então o espaço físico tem algumas necessidades de melhoria. [...]. Mas essa parte aí, com relação aos professores, com relação à atenção dos profissionais da escola, nós estamos felizes pelo que estão oferecendo para gente (FAMILIAR 2 DO MUNICÍPIO SÃO MATEUS).

Essa sequência de registros suscita reflexões sobre a imbricação entre as diretrizes legais instituídas e o trabalho educativo realizado em escolas que contam com a matrícula de estudantes com deficiência. Atentemos para a afirmação dos participantes, quando avaliam a trajetória inclusiva escolar nas realidades que investigamos. Para eles, "“...] a política pública 
avançou muito, [...] está garantida na legislação, mas ainda precisa ser concretizada na prática $[\ldots]$ ". Consideram ainda que "[...] tudo demora muito para chegar na escola [...]" e que "[...] as políticas públicas não têm acompanhado esse ingresso das crianças nas escolas [...]”.

No debate sobre essas questões, consideramos importante não perder de vista que, na atual conjuntura, as forças econômicas têm se sobreposto às demais forças (grupos sociais, militâncias partidárias, grupos religiosos, interesses classistas, interesses de camadas populares) e têm interferido, de forma específica, nas decisões governamentais. Diretamente vinculada a esse processo, a precarização do trabalho docente tem-se agravado no Brasil, no curso das últimas décadas do século XX, em pleno movimento político marcado pela defesa da universalização escolar.

Assumindo a perspectiva histórica e sociológica desenvolvida por Elias $(1993,2008)$, consideramos adequado localizar essas indicações no movimento histórico de longa duração, no qual o Estado moderno alcançou legitimidade. Localizar, dessa maneira, o debate sobre as condições de realização da escola inclusiva em nossas sociedades nos impõe acolher o importante papel que os organismos multilaterais vêm assumindo na composição e na coordenação de uma agenda política que objetiva consolidar a democracia liberal e, complementarmente, considerar a centralidade que esses organismos multilaterais - Banco Mundial (BM), Organização das Nações Unidas para a Educação, a Ciência e a Cultura (UNESCO), Organização Mundial de Comércio (OMC), Organização para Cooperação e o Desenvolvimento Econômico (OCDE) - têm assumido na condução das políticas educacionais em países periféricos ao capitalismo mundial.

Considerando os vieses ideológico e teórico, por meio dos quais esses organismos vêm estabelecendo suas ações, é de fácil percepção o fato de que as políticas locais, ao se alinharem às diretrizes desses organismos, precisam atuar de maneira bastante restritiva $\mathrm{e}$ cautelar para prover meios e recursos que efetivamente facilitem e impulsionem os processos educativos escolares das pessoas com deficiência. Afinal, o indivíduo é aqui pensado como partícula separada da sociedade e, desse modo, os problemas e desafios que obstaculizam sua participação social devem ser "resolvidos" no âmbito particular. Em outros termos, a situação social vivida pelo indivíduo resulta inequivocamente de suas escolhas pessoais. Constituído num vácuo social, o indivíduo tem a "última palavra" e define, por si mesmo, as melhores formas de engajamento na sociedade, independentemente de sua condição econômica, física, sensorial, étnica e/ou de gênero.

Acreditamos que, sob essa perspectiva, um modo peculiar de realizar a inclusão escolar de pessoas com deficiência vem sendo colocado em ação em diferentes realidades de nossas sociedades ocidentais. Assim, a escassez de espaços, materiais, recursos, a morosidade da atuação estatal e o reduzido quantitativo de profissionais do trabalho escolar representam tão-somente a condição necessária à consolidação do sucesso da instituição escolar no Estado liberal. ${ }^{7}$ Mais exatamente, nessa dinâmica social, a precariedade desses

Compreendemos o termo Estado liberal no sentido da defesa dos ideários burgueses difundidos no seio da formação do Estado moderno, o qual tem sido fortalecido em um novo contexto histórico e social nos dias de hoje. Tais ideários se expressam como defesa à propriedade privada e à pouca intervenção estatal nas ações do mercado, cabendo ao Estado, por meio das leis, garantir a livre concorrência com mecanismos de valorização aos setores privados da sociedade. 
elementos, comumente caracterizados como condições objetivas do/no trabalho escolar, não constitui barreira à inclusão educativa de pessoas com deficiência. Diferentemente disso, na perspectiva desses organismos multilaterais, a desinformação, o baixo quantitativo de profissionais disponibilizados para atuar na escola e as precárias condições de acesso ao conhecimento escolar constituem elementos absolutamente pertinentes na construção dos modos como os pais, os profissionais e os estudantes devem materializar a inclusão escolar das pessoas com deficiência no bojo do Estado moderno, guardião dos direitos sociais. Compreendemos que na política que vai se instituindo nesse processo, o compartilhamento da baixa expectativa de que a escola de ensino comum possa, efetivamente, responder às demandas educativas das pessoas com deficiência acentua e legitima o poder social das instituições filantrópicas e/ou do terceiro setor especializadas em Educação Especial. Justificando, por exemplo, o estabelecimento de mecanismos legais que assegurem o financiamento público às instituições de natureza privada que, em tese, poderiam dar melhores respostas às demandas e necessidades educativas das pessoas com deficiência e/ou com transtornos globais do desenvolvimento.

Ocorre que, embora essas condições/situações sociais constituam aspectos importantes do debate sobre os modos como realizamos as políticas de inclusão escolar em território brasileiro, apoiados em Elias, observamos que outras questões se colocam nesse processo com evidente potencial para redimensionar as chances de poder vividas nessa intricada rede de interdependências.

Assumindo o modelo de jogo como perspectiva teórica de análise da dinâmica social, Elias (2008) nos ajuda a compreender que as atitudes e as ações de um grupo não podem ser explicadas nem entendidas a partir de si mesmas, fora da vinculação estabelecida entre parceiros e também entre os adversários. Conforme orienta o autor, em jogo, "[...] os movimentos de um grupo determinam os movimentos do outro grupo e vice-versa" (ELIAS, 2008, p. 83). Essa perspectiva evidencia a impossibilidade de um planejador externo controlar irrestritamente os processos educativos escolares que vimos realizando. Nessa dinâmica, se, por um lado, os governos locais podem funcionar como importantes dispositivos de realização das expectativas economicistas dos agentes internacionais, por outro, no fluxo do jogo social vivido, esses governos locais também podem atuar no sentido de ampliar gradativamente a sua margem de poder na condução das políticas educacionais locais.

Essa percepção subsidia a nossa expectativa positiva quanto à importância dos nossos investimentos políticos na sociedade atual. Fundamentado na noção de figuração social, Elias $(1993,2008)$ nos mostra que a vida em sociedade é balizada por uma ordem imanente. Esclarece-nos, assim, que nossos atos e nossos desejos orientam as figurações sociais no aqui e agora, mas a ambivalência e as ambiguidades de interesses e de expectativas que significam e justificam os nossos atos e os nossos desejos no interior dessas figurações conferem, no curso do tempo e das tensões vividas, imanência às figurações sociais, constituindo processos sociais não planejados.

Esse importante aspecto nos permite compreender que a Sociologia figuracional constitui uma sociologia crítica e politicamente envolvida. Da forma trabalhada por Elias, a 
complexidade que narra os entrelaçamentos humanos em nossas sociedades ocidentais comporta expectativas e atos de mudanças, de rupturas, de continuidades e de resistências, todos em dimensões mutáveis e incertas. A última palavra ou o fim da história não estão dados. Estão em via de construção, numa sociodinâmica que amplia e aprofunda as interdependências sociais e, nesse sentido, supõe o nosso engajamento e a nossa participação.

\section{CONSIDERaÇões Finais}

As reflexões aqui empreendidas nos provocam considerar que estudar a trajetória das políticas educacionais implica perceber a imbricação entre outras trajetórias de diferentes dimensões: a dos sujeitos e a dos grupos envolvidos; a dos mecanismos legais e a de atuação das equipes de governos. Nenhuma dessas três dimensões se realiza de maneira independente e isolada. Do ponto de vista da inclusão escolar, o acesso e a permanência de pessoas com deficiência à escola de ensino comum assumem diferentes contornos, os quais são delineados conforme o que expressam os mecanismos legais em articulação com o trabalho realizado pelas equipes de governo. Mais pontualmente, a política instituída vai não só delineando um modo particular de ser aluno e de ser professor, mas também impulsionando os nossos investimentos pessoais na ampliação de matrículas em escolas de ensino comum, na identificação de recursos, de materiais e de espaços favoráveis àquilo que, num dado momento, expressa a inclusão escolar.

Observamos que essas questões surgiram nos discursos dos sujeitos participantes dos grupos focais realizados nos dois municípios brasileiros envolvidos na investigação, sobretudo quando propusemos discussões a respeito da escola como espaço de aprendizagem, a dinâmica de intersetorialidade nos processos educativos de estudantes com deficiência, bem como, acerca da trajetória das políticas de inclusão escolar. Quando focalizaram o papel dos governos locais e dos mecanismos legais no processo de inclusão escolar, os participantes dos grupos focais sinalizaram indícios em determinada direção, que está em curso, favorável à democratização do acesso e da permanência de alunos em situação de deficiência no contexto escolar. Mesmo destacando os dilemas e os desafios para que esse processo se concretize, os sujeitos apontaram, em vários momentos, as possibilidades e as realizações ocorridas nos cotidianos das escolas, em decorrência das políticas implementadas pelos governos locais.

Olhar os processos políticos desse ponto de vista e nessa direção, considerando o envolvimento e o engajamento de quem executa a política no cotidiano das secretarias de educação e das escolas, significa perceber que as manifestações nos espaços micropolíticos provocam, numa rede de interdependência, modificações nos espaços macropolíticos. A esse respeito, com base em Elias (1993), podemos considerar que as redes de relacionamentos humanos nos espaços cotidianos estão imbricadas nos processos sociais e que as transformações nesses processos são possíveis mediante o conjunto de combinações desses diversos relacionamentos humanos. 
Nessa perspectiva, se as políticas materializadas pelas equipes de governo definem, em grande medida, os modos de incluir na escola, não podemos perder de vista que a complexidade que narra os modos de incluir na escola tem também um potencial para o redimensionamento e/ou a reelaboração dessas mesmas políticas.

Nesses termos, consideramos importante a construção de movimentos que valorizem a constituição humana nas redes de relações sociais. Por isso, acreditamos na importância de compreender o indivíduo no fluxo dos processos sociais; afinal, em Elias, os indivíduos somente podem ser entendidos nas teias de relações e nas interdependências que constituem entre si e com os "outros".

Com base nessa compreensão, vale considerar que os processos políticos, pela via das legislações, foram delineando conquistas sociais como direitos, na medida em que os indivíduos tinham seus habitus e estruturas psíquicas modificadas (psicogênese) em meio às mudanças ocorridas na sociedade como um todo (sociogênese). Ocorre, assim, uma compreensão positiva de que "há um processo em curso", exatamente à medida que os indivíduos passam a valorizar determinados comportamentos, procedimentos, atitudes que antes e, possivelmente, em outras sociedades não alcançariam esse mesmo sentido e essa mesma importância.

Diante dessa reflexão, é necessário ainda considerar que trabalhar em prol da escola pública com qualidade é almejar que, entre diversos fatores, a presença do aluno com deficiência na escola produza movimentos entre os profissionais na construção de práticas pedagógicas que contribuam para os processos de aprendizagem de todos. Nessa direção, mudanças no plano das ideias são necessárias, assim como nos modos e atitudes dos indivíduos, na cultura, na concepção de políticas públicas e educacionais, nos investimentos, na valorização da carreira do magistério, nas metodologias de ensino e processos avaliativos.

Por outra via, no conjunto das figurações sociais existem outros movimentos com dimensões mais alargadas. No plano político, a intensificação, a diferenciação e a crescente especialização do trabalho nas sociedades ocidentais vêm ampliando e aprofundando a complexidade das cadeias de ações individuais. Esse processo guarda uma inusitada peculiaridade: acentua e legitima a necessidade da preservação de um órgão central, dotado de alto nível de organização, capaz de coordenar e de regular as tensões vividas nas mais diferentes figurações sociais. É nesse complexo processo social que, em território brasileiro, vamos produzindo crenças, expectativas e concepções específicas a respeito do papel dos governos locais e dos mecanismos legais na inclusão escolar que realizamos cotidianamente.

\section{REFERÊNCIAS}

BRASIL. Ministério da Educação. Política Nacional de Educação Especial na Perspectiva da Inclusão Escolar, 2008. Secretaria de Educação Especial. Disponível em: <portal. mec.gov.br/seesp/arquivos/pdf/politica.pdf > . Acesso em: 27 jan. 2017. 
CARVALHO, E. J. G. de. Estudos comparados em educação: novos enfoques teórico- metodológicos. Acta Scientiarum Education, v. 36, n. 1, Maringá, jan./jun. 2014, p. 129-141. COSTA, G. S. Grupos focais: um novo olhar sobre o processo de análise das interações verbais. Revista Intercâmbio, v. 25, São Paulo, 2012, p. 153-172. ISSN 2237-759x.

ELIAS, N. Introdução à sociologia. Lisboa: Edições 70 LTDA, 2008.

. Processo Civilizador: formação do Estado e civilização, v. 2. Rio de Janeiro: Zahar, 1993.

FERREIRA, A. G. O sentido da Educação Comparada: Uma compreensão sobre a construção de uma identidade. Educação, v. 31, n. 2, Porto Alegre, mai./ago. 2008, p. 124-138.

FONSECA, M. O Banco Mundial como referência para a justiça social no terceiro mundo: evidências do caso brasileiro. Rev. Fac. Educ., v. 24, n. 1. São Paulo, jan.jun. 1998. Disponí-

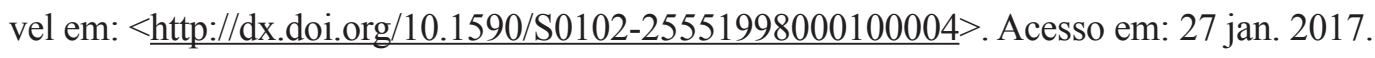

GATTI, B. A. Grupo focal na pesquisa em ciências sociais e humanas. Brasília: Líber Livro Editora, 2005.

GEBARA, A. Violências e percepções: a escola como local privilegiado. In: II Jornandas Internacionales: "Sociedades Contemporáneas, Subjetividad Y Educación, 2014. Buenos Aires. Anais... Buenos Aires, 2014. CD.

GONDIM, S. M. G. Grupos Focais como Técnica de Investigação. Paidéia, v. 12, n. 24, p. 149-161, 2003.

HAMUI-SUTTON, A.; VARELA-RUIZ, M. La técnica de grupos focales. Inv Ed Med, v. 2, n. 1, p. 55-60, 2013.

HOBSBAWM, E. J. A Era dos Extremos: o breve século XX. São Paulo: Companhia das Letras, 1995.

A Era das revoluções (1789-1848), 35. ed. Rio de Janeiro: Paz \& Terra, 2015.

HONORATO, Tony. A escola como um lugar de poder onde as individualizações se encontram. In: II Jornandas Internacionales: "Sociedades Contemporáneas, Subjetividad Y Educación, 2014. Buenos Aires. Anais... Buenos Aires, 2014. CD.

INSTITUTO Brasileiro de Geografia e Estatística. Censo Demográfico 2010, Dados do Universo. Disponível em: $<$ http://www.cidades.ibge.gov.br/xtras/perfil.php?lang=\&codm

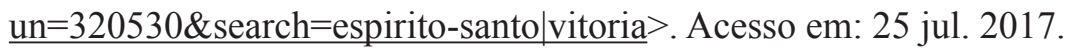

. Censo Demográfico 2010, Dados do Universo. Disponível em: $<\underline{\text { http://www. }}$ cidades.ibge.gov.br/xtras/perfil.php?lang=\&codmun=320490\&search=espirito-santo|sao-mateus $>$. Acesso em: 25 jul. 2017.

MILANEZI, T. C. M. Inter-relações surdos e ouvintes no processo de apropriação do conhecimento escolar por estudantes surdos, 2016, 164s. Dissertação (Mestrado em 
Educação). Programa de Pós-Graduação em Educação, Universidade Federal do Espírito Santo, Vitória, 2016.

MOTA JUNIOR, W. P.; MAUÉS, O. C. O Banco Mundial e as Políticas Educacionais Brasileiras. Educação \& Realidade, v. 39, n. 4, Porto Alegre, out./dez. 2014, p. 1.137-1.152. Disponível em: < http://www.ufrgs.br/edu_realidade>. Acesso em: 28 jan. 2017.

RENAN, E. In: SMITH, A.¿ Gatronomia e geologia? El rol del nacionalismo en la reconstrucción da las naciones. In: FERNÁNDEZ BRAVO, Álvaro (comp.). La invención de la nación. Lecturas de la identidad de Herder a Homi Bhabha. Buenos Aires: Manatial, 2000.

SANDER, B. Políticas Públicas e Gestão Democrática da Educação. Brasília: Liber, 2005.

SANTOS, B. F. d; PORRO, S. O grupo focal na pesquisa sobre o ensino de química: mapeando representações docentes. Encontro Nacional de Ensino de Química, 14, 2008, Curitiba. Anais. Curitiba: UFPR, 2008.

SOTO, A. P. O. M.; ZICHIA, A. C.; GONZALEZ, R. K.; PRIETO, R. G. Financiamento da Educação Especial no brasil na arena do público e do privado. P o i é s i s - Revista do Programa de Pós-Graduação em Educação - Mestrado - Universidade do Sul de Santa Catarina, v. 6, n. 10, Tubarão, 2012, p. 359-376.

TELLO, C.; MAINARDES, J. A educação secundária na América Latina como direito democrático e universal: uma análise de documentos do Banco Mundial e do Banco Interamericano de Desenvolvimento. Revista Educação e Filosofia Uberlândia, v. 28, n. especial, 2014, p. 155-179.

VALADÃO, V. A crítica de Hayek e Friedman ao Estado de Bem-Estar. Interface, n. 3, Vitória, nov. 1997, p. 9-34.

VEIGA, C. G. Reglamentación del trabajo infantil y tensiones con la escolarización, Brasil (1890-1944). In: XV Simpósio Internacional Processos Civilizadores, 2014. Cidade do México. Anais... Cidade do México, 2014. 1 CD.

ZIVIANI, M. C. N. Interdependência e colaboração em contextos escolares inclusivos, 2016, 162s. Dissertação (Mestrado em Educação) - Programa de Pós-Graduação em Educação. Universidade Federal do Espírito Santo, Vitória, 2016.

Dados dos AUTORES

\section{Reginaldo Celio Sobrinho}

Doutor em Educação pela Universidade Federal do Espirito Santo. Docente do Programa de Pós-Graduação em Educação da Universidade Federal do Espírito Santo. Vitória/ES Brasil.reginaldo.celio@ufes.br 


\section{Edson Pantaleão Alves}

Doutor em Educação pela Universidade Federal do Espirito Santo. Docente do Programa de Pós-Graduação em Educação da Universidade Federal do Espírito Santo. Vitória/ES Brasil.edpantaleao@hotmail.com

\section{Elaine de Carvalho}

Mestre pelo Programa de Pós-Graduação em Educação da Universidade Federal do Espirito Santo. Docente do Sistema Municipal de Ensino da Serra. Serra/ES - Brasil.

1976carvalhoaaa@gmail.com

Submetido em: 18-8-2017

Aceito em: 4-12-2017 